\title{
Gas Condensate Valorization with Compounding of Ethane by Pyrolysis Process
}

Mimoun $\mathbf{H}^{*}$, Bouarar F, Kaddour $\mathbf{O}$ and Khettab $\mathbf{N}$

Laboratory of Technology of Hydrocarbons, University of Boumerdes and USTHB, Algeria

\begin{abstract}
The Algerian gas condensate may be valuated as a raw matter to obtain maximum ethylene and propylene yields, the latter are used as first materials to produce polyethylene and polypropylene. It is judged utile to substitute ethane as pyrolysis feedstock by the Algerian condensate compounded with ethane. Several dilutions $(5 \%, 10 \%$ and $20 \%$ ) of the gas condensate and its fractions with ethane have been prepared to be used as pyrolysis feedstock. The effect of temperature, residence-time and steam flow on the yield of pyrolysis products have been studied well as their influence on the composition of pyro gas and liquid pyrolysis.
\end{abstract}

Keywords: Gas condensate; Ethane; Pyrolysis; Olefins

\section{Introduction}

Several charges are used for the production of olefins through pyrolysis: gaseous hydrocarbons, liquefied gases, light gasoline and heavy fractions of hydrocarbons $[1,2]$. However, ethane and naphtha constitute the principal feedstock pyrolysis, depending on their abundance and their price [3].

The gas condensates in Algeria occupy a second place after crude [4]. Important products as olefins and aromatic hydrocarbons could be obtained from the Algerian gas condensates [5] which are composed of paraffin's, naphthenic and a small amount of aromatic hydrocarbons, seen the diversity of product range that provides which benefit processes such as alkylation, polymerization. The olefin hydrocarbons serve as feedstock for the production of polymers and aromatic hydrocarbons [6].

The present work aims to investigate the potential of using Algerian gas condensates and its fractions obtained from the fractionation of the condensate compounded with ethane during the pyrolysis process. The objective is also to analyses the influence of changes in operating conditions (temperature, steam, residence time) on the pyrolysis products in order to improve their content of olefins (ethylene, propylene...etc.) and aromatics (benzene, toluene and xylene) which are used as feedstock for petro chemistry.

\section{Research Methodology}

\section{Materials}

Table 1 summarizes the physico-chemical characteristics of gas condensate. The distillation curve $\left({ }^{\circ} \mathrm{C}\right)$ and hydrocarbon composition of gas condensate are as follows in Table 2.

\section{Implementation condensate}

A further distillation was carried out to fractionate the crude condensate in three cuts:
1) $18^{\circ} \mathrm{C}$ to $90^{\circ} \mathrm{C}$ (Light fraction)
2) $90^{\circ} \mathrm{C}$ to $180^{\circ} \mathrm{C}$ (Medium fraction)
3) $>180^{\circ} \mathrm{C}$ (Residue fraction)

\section{Procedures}

The pyrolysis was conducted in a straight-through unit, which

\begin{tabular}{|l|l|}
\hline Characteristics & Results \\
\hline Density at $15^{\circ} \mathrm{C}$ & 0.7216 \\
\hline Refractive index at $20^{\circ}$ & 1.4105 \\
\hline Aniline point $\left({ }^{\circ} \mathrm{C}\right)$ & 64 \\
\hline Molecular Mass $\mathrm{g} / \mathrm{mol}$ & 118.7 \\
\hline & PONA Analysis $(\%$ weight $)$ \\
\hline $\mathrm{P}(\mathrm{n}, \mathrm{i})$ & $62,19(45,77 ; 16,42)$ \\
\hline $\mathrm{N}$ & 6.13 \\
\hline 0 & 0 \\
\hline A & 5.89 \\
\hline Unidentified paraffin & 25.79 \\
\hline
\end{tabular}

Table 1: Physico-chemical characteristics of gas condensate.

\begin{tabular}{|l|l|}
\hline IP & 36 \\
\hline $5 \%$ & 51 \\
\hline $10 \%$ & 62 \\
\hline $20 \%$ & 73 \\
\hline $30 \%$ & 85 \\
\hline $40 \%$ & 96 \\
\hline $50 \%$ & 111 \\
\hline $60 \%$ & 134 \\
\hline $70 \%$ & 157 \\
\hline $80 \%$ & 182 \\
\hline $90 \%$ & 227 \\
\hline $95 \%$ & 271 \\
\hline EP & 279 \\
\hline Distillate & 97 \\
\hline Residue & 1 \\
\hline Losses & 2 \\
\hline
\end{tabular}

Table 2: Distillation curve $\left({ }^{\circ} \mathrm{C}\right)$.

"Corresponding author: Mimoun $\mathrm{H}$, Laboratory of Technology of Hydrocarbons, University of Boumerdes and USTHB, Algeria, Tel: +213 247952 75; E-mail: mimounhadj@yahoo.fr

Received April 18, 2018; Accepted April 18, 2018; Published May 31, 2018

Citation: Mimoun H, Bouarar F, Kaddour O, Khettab N (2018) Gas Condensate Valorization with Compounding of Ethane by Pyrolysis Process. J Pet Environ Biotechnol 9: 363. doi: 10.4172/2157-7463.1000363

Copyright: (c) 2018 Mimoun H, et al. This is an open-access article distributed under the terms of the Creative Commons Attribution License, which permits unrestricted use, distribution, and reproduction in any medium, provided the original author and source are credited. 
includes a heating section, ethane bottle, a reactor with two connected tanks - for delivery of feedstock, and water for its dilution, a section for cooling and receiving of the pyrolysis products [7]. The reactor was placed in a cylindrical heating furnace. After heating to the assigned temperatures $\left(720^{\circ} \mathrm{C}, 760^{\circ} \mathrm{C} 800^{\circ} \mathrm{C}\right.$ and $\left.840^{\circ} \mathrm{C}\right)$ the condensate and water were delivered into the furnace at a rate Steam/Hydrocarbon, steam flow; hydrocarbons flow (condensate + ethane) with a report that differs according to the test. The gas and liquid products obtained were passed through a cooler into a gasometer and tank, respectively. Samples of these products were analyzed by the chromatographic method. These conditions were selected as optimum based on previous studies [8-11].

\section{Result and Discussion}

Steam cracking of crude condensate and these fractions compounded with ethane

Various dilutions (5\%, 10\%, and 20\%) crude condensate and these fractions compounded with ethane were prepared for their use as raw material for the pyrolysis process.

\section{A. Influence of temperature on the yield of pyrolysis products}

A-1- Steam cracking of crude condensate compounded with ethane the operating conditions:

Hydrocarbons flow (condensate + ethane $)=43.02 \mathrm{~g} / \mathrm{h}$

Steam flow $=21.51 \mathrm{~g} / \mathrm{h}$

Ratio $=$ Steam $/$ Hydrocarbon $=0.5$

Results showing the influence of temperature on the yield of pyrolysis products of condensate compounded with ethane (Figures 1 and 2). The best experimental results were achieved by dilution of $5 \%$ condensate with ethane. With increasing temperature, pyro gas content varies from 65 to $83 \%$, that liquid pyrolysis varies from $32 \%$ to $15 \%$ and increased the amount of coke. For the first test (5\% condensate), the amounts of ethylene and propylene increase with increasing of temperature with maximum yields of ethylene at $84^{\circ} \mathrm{C}$ and Propylene at $760^{\circ} \mathrm{C}$. for samples with $10 \%$ and $20 \%$ condensate. The quantity obtained of gas pyrolysis relatively decreases compared to the samples in $5 \%$ against the yields of coke and liquid pyrolysis increase relatively. When the concentration of condensate increases, liquid pyrolysis content decreases at an expense of formation of coke.

A-2-Steam cracking of light fraction condensate compounded with ethane: For the light fraction, in the same tests and under the same conditions were carried out for the condensate. The results show that the gas pyrolysis contents, ethylene and propylene are superior Compared to those obtained by the condensate against, those of liquid pyrolysis and coke decrease. The increasing concentration of the light fraction decreases slightly gas pyrolysis content, against of liquid pyrolysis, increases due to the condensation of olefins to aromatic (Figures 3 and 4 ).

A-3-Steam cracking of the medium condensate fraction compounded with ethane operating conditions:

Hydrocarbons flow $=44.1 \mathrm{~g} / \mathrm{h}$

Steam flow $=22.05 \mathrm{~g} / \mathrm{h}$

Ratio $=$ Steam $/$ Hydrocarbon $=0.5$

For the medium fraction; the behavior during the pyrolysis is

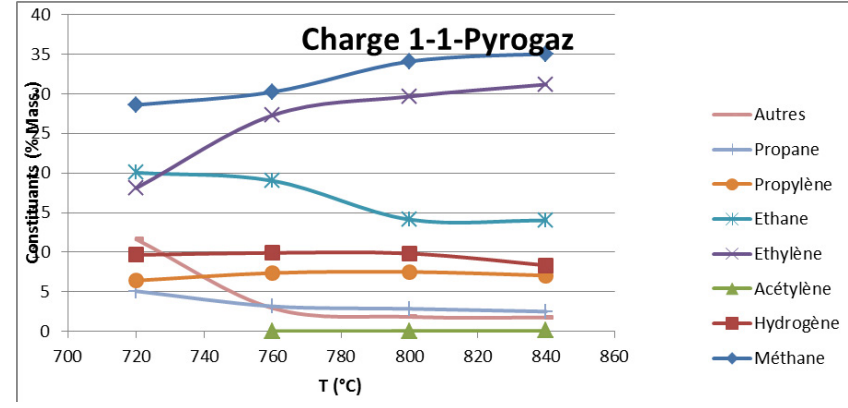

Figure 1: Effect of temperature on the yield of pyro gas.

\section{Charge 1-1-Brai de pyrolyse}

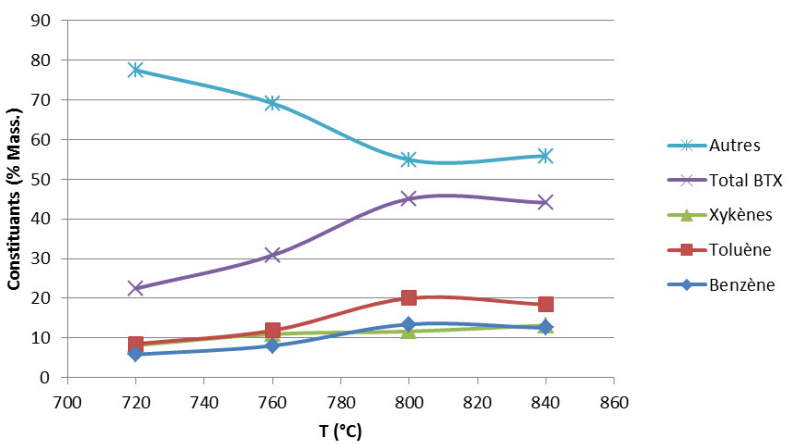

Figure 2: Effect of temperature on the yield of liquid pyrolysis.

approximately the same as the condensate. The results relating to the composition of the constituents, the pyro gas contents and liquid pyrolysis are substantially identical to those obtained for condensate. This is due to the high content of this fraction in the condensate. This is due to the high content of this fraction in the condensate.

A-4-Steam cracking of the heavy fraction of the condensate compounded with ethane: For the residue, the tests showed strong coke content which does not allow to Feedstock the value as a commercial scale. It is found that the pyro gas content increases and the liquid pyrolysis decreases. Compared to other fractions of the condensate pyro gas and liquid pyrolysis contents are relatively low.

B. Influence of the injection of steam on the performance of the pyrolysis products

B-1-Steam cracking of crude condensate compounded with ethane operating conditions:

Hydrocarbons flow $=43.02 \mathrm{~g} / \mathrm{h}$

All tests were carried out following; Ratio=Steam/hydrocarbon $=$ $0.3,0.4,0.5$ and 0.6 .

It has been noticed at $840^{\circ} \mathrm{C}$, that the increase in injecting steam decreases the content in coke and favorites the formation of the unsaturated hydrocarbons. At $760^{\circ} \mathrm{C}$, the content of coke is relatively weak compared to a process done at $840^{\circ} \mathrm{C}$. These operating conditions have permitted to obtain a weak variation of propylene content. concerning the liquid pyrolysis product at $760^{\circ} \mathrm{C}$, the content in BTX rises with the decrease of the steam injection, which may be explained just at this temperature, the reactions of condensation are relatively weak ( coke formation). The best experimental results are illustrated 


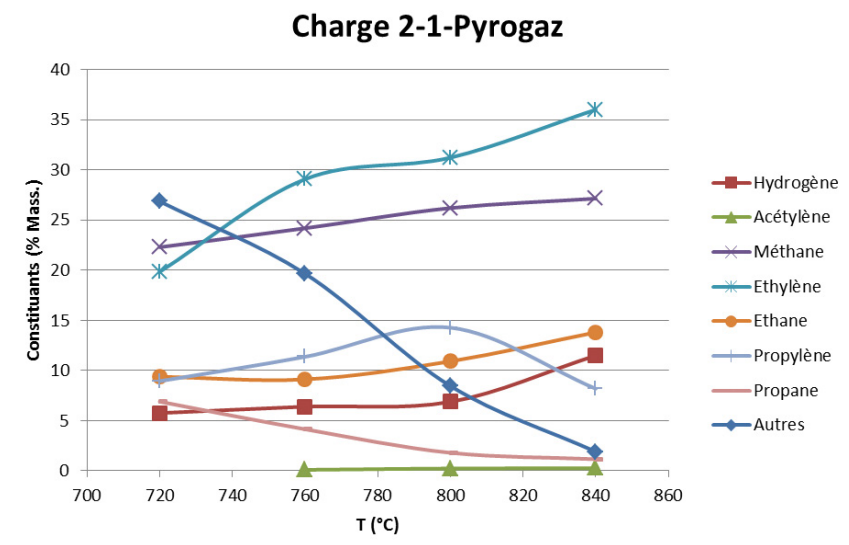

Figure 3: Effect of temperature on the performance of pyro gas.

\section{Charge 2-1-Brai de pyrolyse}

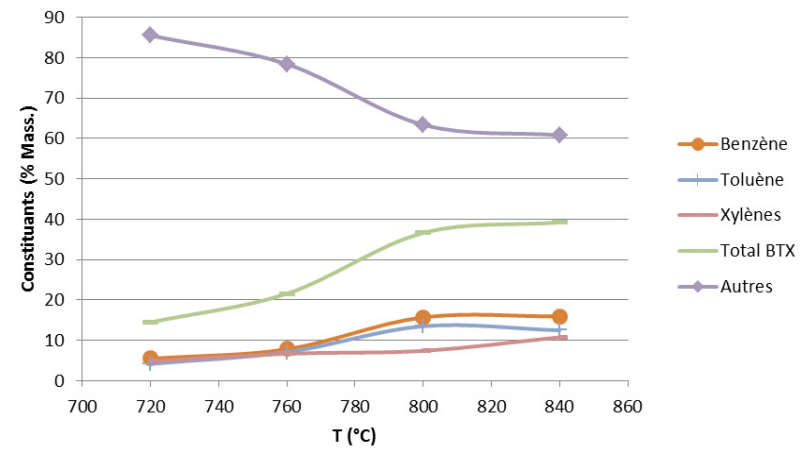

Figure 4: Effect of temperature on the performance of liquid pyrolysis.

(Figures 5 and 6 ) which was achieved by dilution $5 \%$ of condensate with ethane.

B-2-Steam cracking of light fraction condensate compounded with ethane: The tests were carried out in the same conditions as those of the condensate. The best experimental results are illustrated (Figures 7 and 8 ) which was achieved by dilution of $20 \%$ of light fraction condensate compounded with ethane. For the light fraction, the increase of steam injection raises the amount of ethylene.

B-3-Steam cracking of the average condensate fraction compounded with ethane: For the average fraction, the steam injection at $760^{\circ} \mathrm{C}$ promotes increased of the liquid pyrolysis quantity. We also remark a decrease of coke quantity. At this temperature, steam injection favorites the formation of propylene; by contrast the content of ethylene remains at $840^{\circ} \mathrm{C}$, in the liquid pyrolysis product, the formation of the BTX is favored (de alkylation's reaction).

B-4-Steam cracking of the heavy condensate fraction compounded with ethane: The best experimental results were achieved by using the heavy fraction compound at $5 \%$ with ethane. For the heavy fraction, influence of steam favorites the formation of the pyrolysis gas and the liquid pyrolysis. For the pyrolysis gas, the Content of propylene increases and the liquid pyrolysis product is composed of BTX and alkyl benzene.

At $840^{\circ} \mathrm{C}$, the content of alkyl benzene decrease with steam injection. The content of the coke is more very important while using this feedstock but, it has been noticed that its content decreases

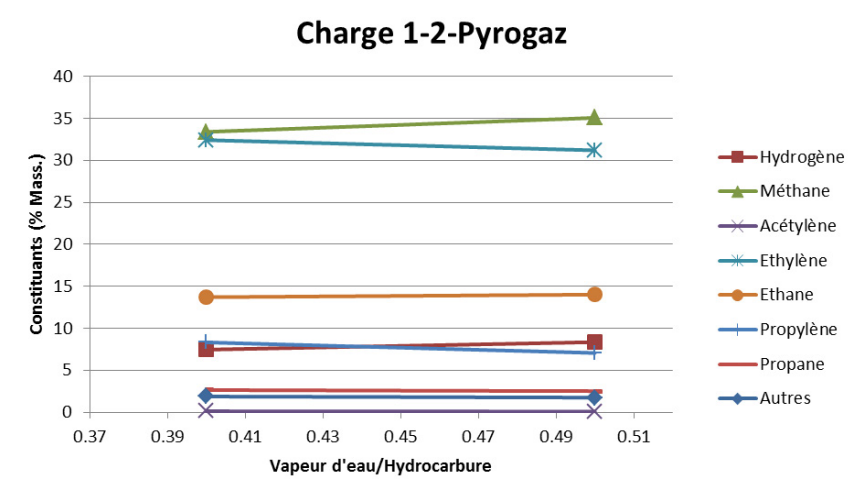

Figure 5: Effect of the injection of steam on the performance of pyrogas.

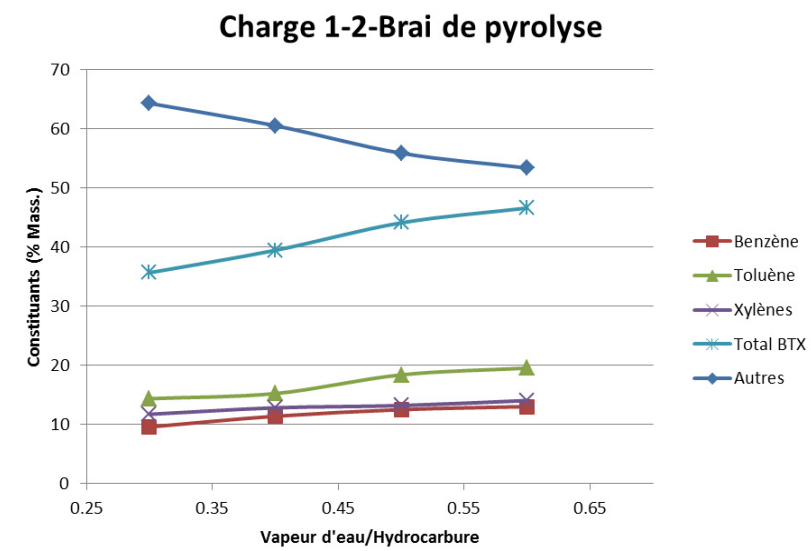

Figure 6: Effect of the injection of steam on the performance of liquid pyrolysis.

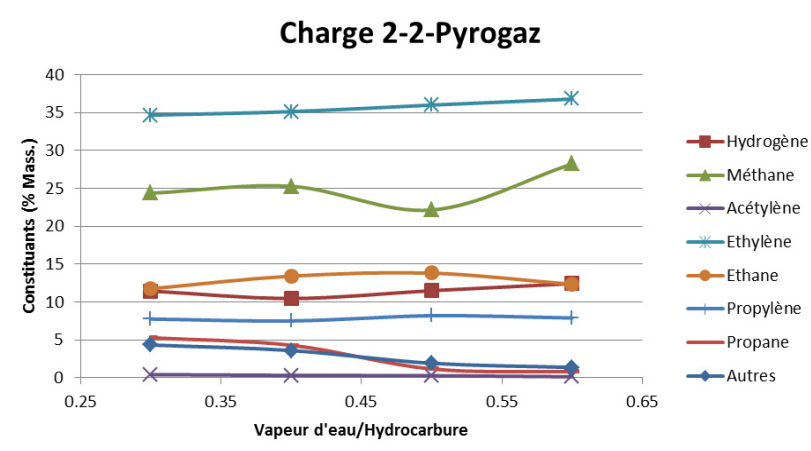

Figure 7: Effect of the injection of steam on the performance of pyrogas.

relatively with increase of steam injection. On the basis of these results, we notice the regular rise of the pyrolysis gas quantity and a decrease in the liquid pyrolysis and coke.

C-Influence of the residence time on the performance of the pyrolysis products

C-1-Steam cracking of crude condensate compounded with ethane: The temperature $840^{\circ} \mathrm{C}$ is realized for all the different feedstock, against of $760^{\circ} \mathrm{C}$ is defined just for the charge containing the average condensate fraction. The residence time is assimilate to the variation of flow while maintaining the Ratio=Steam $/$ Hydrocarbons $=0.5$.

Experimentally, the measured contact time has been determined by varying the feedstock flow. Steam dosage has been defined with 


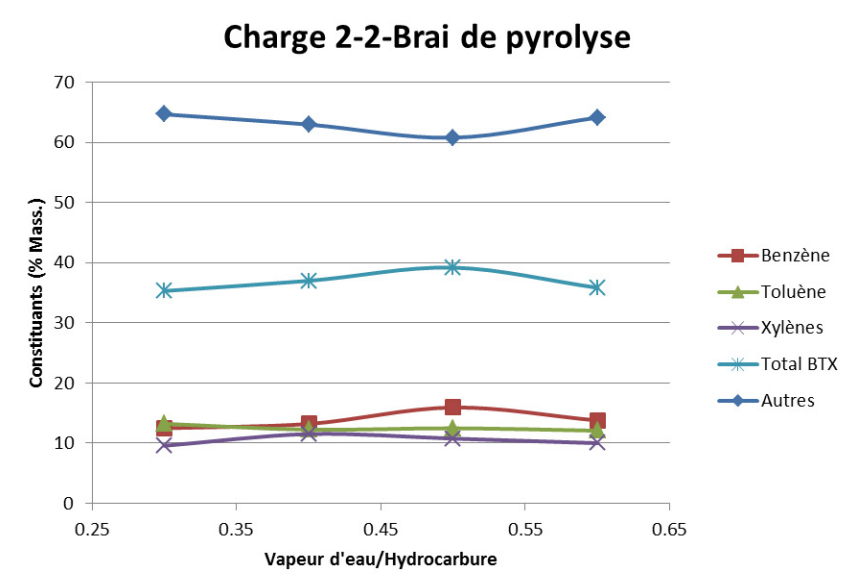

Figure 8: Effect of the injection of steam on the performance of liquid pyrolysis.

function of ethylene, propylene and the liquid pyrolysis product yields. Taking into consideration, the defined temperatures in the experiments previously realized at $840^{\circ} \mathrm{C}$ and $760^{\circ} \mathrm{C}$, we have proceeded at the variation of contact time. Concerning the compound condensate at $840^{\circ} \mathrm{C}$, the yield of the pyrolysis gas increases oppositely to that of the liquid pyrolysis with contact time of till a certain value where the content of the liquid pyrolysis decrease and that of the coke increase. At $760^{\circ} \mathrm{C}$, we observe the same variations as the previous ones, except that the content of the propylene is weaker (Figures 9 and 10).

C-2-Steam cracking of light fraction condensate compounded with ethane: The tests were carried out in the same conditions as those of the condensate. For the light fraction at $840^{\circ} \mathrm{C}$, we obtain more pyro gas rich with ethylene. At $760^{\circ} \mathrm{C}$, the content of the propylene increases as the one of the ethylene but in a less marked manner. The liquid pyrolysis remains unchangeable.

C-3-Steam cracking of the average condensate fraction compounded with ethane: The temperature is maintained at $760^{\circ} \mathrm{C}$ for a maximum yield of propylene. The best results were achieved by dilution of the condensate with $10 \%$ ethane. For the average fraction, compared to the light fraction, we notice an improvement in the propylene content. It is to state that at a specific threshold of the contact time, the coke content starts to increase (Figures 11 and 12).

C-4-Steam cracking of the heavy condensate fraction compounded with ethane: This test was realized under the same conditions as the previous. Acceptable results are obtained by testing the load compounded at $5 \%$ ethane. For the heavy fraction, we observe a decrease of the pyro gas content as so that of the unsaturated hydrocarbons. The liquid pyrolysis quantity increases but impoverished in the BTX.

\section{The operating parameters optimization}

In order to get a maximum yield in ethylene, propylene and BTX, we have optimized the operatory settings of pyrolysis process using the experiments planning method. The results obtained by the leastsquares method are the following [10]:

- A maximum yield of $36 \%$ in ethylene for a dosage of $10 \%$ of the condensate's light fraction. The process temperature is $820^{\circ} \mathrm{C}$ with a molar report (steam/feedstock $=0.4$ ).

- A maximum yield of $20 \%$ in propylene using the average fraction with a dosage of $10 \%$. The temperature is $720^{\circ} \mathrm{C}$ with a molar report (steam/ feedstock $=0.4)$.

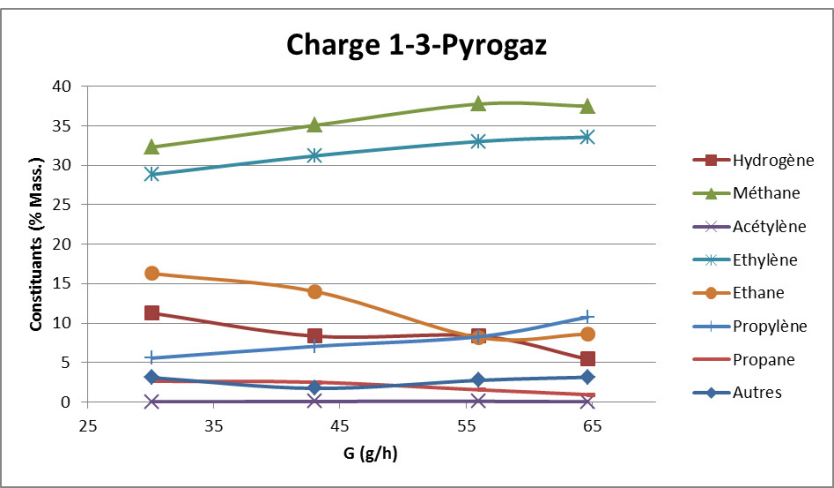

Figure 9: Effect of the residence time on the performance of the pyro gas.

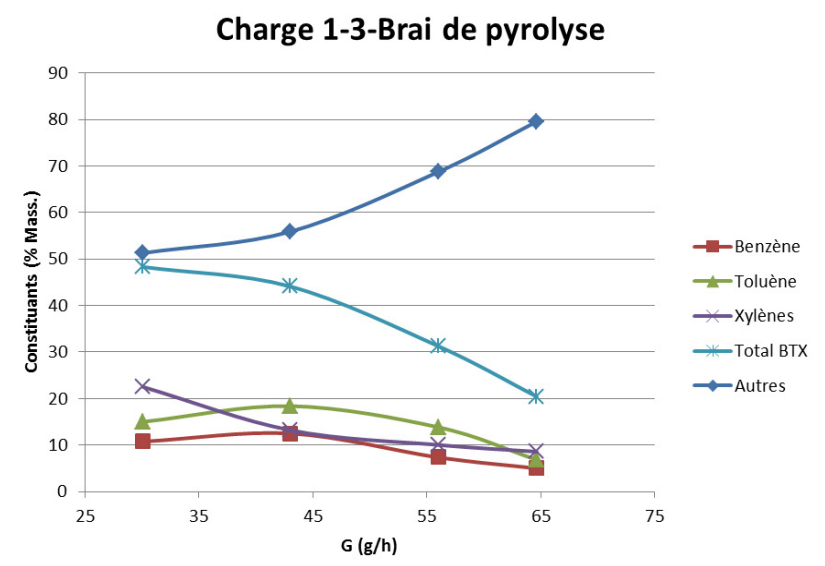

Figure 10: Effect of the residence time on the performance of the liquid pyrolysis C-2- Steam cracking of light fraction condensate compounded with ethane.

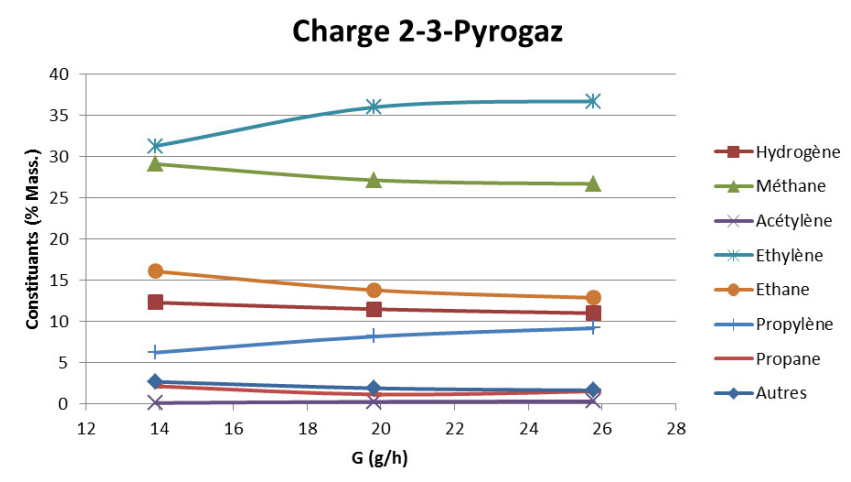

Figure 11: Effect of the residence time on the performance of the pyro gas.

- A maximum yield of $30 \%$ in liquid pyrolysis using the average fraction with a dosage of $20 \%$. The temperature is $720^{\circ} \mathrm{C}$ with a molar report $($ steam $/$ feedstock $=0.5)$.

\section{Conclusions}

1. For the study of the operating parameters optimization, taking into account all the raw materials compound (condensate/ light, average and heavy fractions) with different dosages $(5 \%, 10 \%, 20 \%)$ and the variation of these parameters, the experimental results obtained are: 


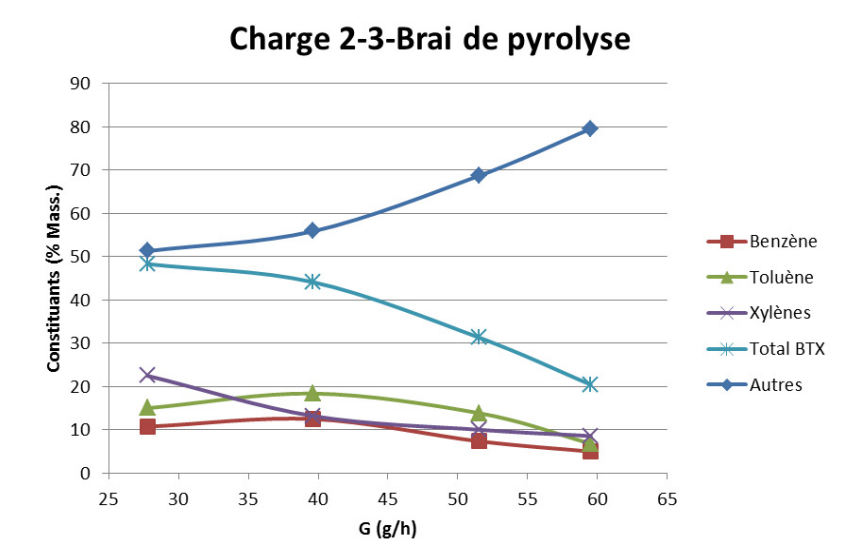

Figure 12: Effect of the residence time on the performance of the liquid pyrolysis C-3- steam cracking of the average condensate fraction compounded with ethane.

2. For a maximum yield of $36 \%$ in ethylene, there must be; a temperature of $840^{\circ} \mathrm{C}$, steam/hydrocarbon equal 0.5 , a contact time 0.15 s and raw material; $20 \%$ of light fraction compound with the ethane.

3. For a maximum yield of $20 \%$ in propylene, there must be; a temperature of $760^{\circ} \mathrm{C}$, the report steam/ hydrocarbon equal 0.5 , a contact time $0.2 \mathrm{~s}$ and raw material; average fraction compound with $10 \%$ ethane.

4. For a maximum yield of $20 \%$ liquid pyrolysis product ( $40 \%$ of BTX), the same conditions may be retained but using as raw material, the average fraction at $20 \%$.
5. The liquid pyrolysis (where the content of the BTX is of 35\%). The yield of the propylene may attain $15 \%$.

\section{References}

1. Sadrameli SM, Green AES (2005) Systematics and modeling representations of naphtha thermal cracking for olefin production. J Anal Appl Pyrolysis 73: 305-313.

2. Ktalkherman MG, Namyatov IG, Emelkim VA, Lomanovich KA (2013) High-selective pyrolysis of naphtha in the fast-mixing reactor. Fuel Process Technol 106: 48-54.

3. Seifzadeh SH, Rahimpour MR, Raeissi S, Dehghani O (2013) Investigation of ethylene production in naphtha thermal cracking plant in presence of steam and carbon dioxide. Chem Eng J 228: 1158-1167.

4. Kaddour O, Sherbi A, Busenna A, Kolesnikov IM (2009) Production of olefin and aromatic hydrocarbons by pyrolysis of gas condensate. Chem Technol Fuels Oils 45: 440-442.

5. Salakhov I, Ekimova AM, Eiyatdinov AS, Diyarov IN (2005) Effect of feedstock hydrocarbon composition on the distribution of products of initiated pyrolysis. Chem Technol Fuels Oils 41: 386-394.

6. Louzazna EH (1995) Valorization of the Algerian condensate by the process of steam-cracking

7. Pintér A, Tungler A, Nagy L, Vida L (2007) Steam-cracking of high molecular weight paraffins. React Kinet Catal Lett 92: 223-230.

8. Lapidus AL, Zhagfarov FG, Grigor'eva NA, Khudyakov DS, Kozlovn AM (2010) Chemical processing of natural gas and gas condensate. Chem Technol Fuels Oils 46: 141-147.

9. Ktalkherman MG, Namyatov IG, Emel'kin VA (2013) Effect of governing parameters on pyrolysis of liquefied petroleum gases in the high temperature heat carrier. Theor Found Chem Engg 47: 667-675.

10. Alieva AM, Tairova AZ, Guseinovaa AM, Ismailov NR (2013) Optimal contro of process of pyrolysis of paraffinic hydrocarbons $\mathrm{C} 2-\mathrm{C} 4$ and their mixtures. Theor Found Chem Engg 47: 406-413.

11. Glebov LS, Glebova EV (2015) Pyrolysis of hydro-treated vacuum gas oil. Petrol Chem 55: 238-240. 